\title{
ANALISIS PENGARUH BAURAN PROMOSI TERHADAP KEPUTUSAN KONSUMEN PADA PT. BANK NEGARA INDONESIA (PERSERO) TBK CABANG MAJENE
}

\author{
Erwin \\ E-mail: erwin@unsulbar.ac.id \\ Fakultas Ekonomi, Universitas Sulawesi Barat \\ Jln. Prof. Dr. Baharuddin Lopa, SH, Talumung, Majene, Sulawesi Barat, 9412 \\ Sri Utami Permata \\ E-mail: sriutamipermata@unsulbar.ac.id \\ Fakultas Ekonomi, Universitas Sulawesi Barat \\ Jln. Prof. Dr. Baharuddin Lopa, SH, Talumung, Majene, Sulawesi Barat, 9412
}

\begin{abstract}
ABSTRAK
Penelitian ini ingin melihat pengaruh promosi penjualan dan periklanan tanpa menyampingkan variabel lain dari bauran promosi, sehingga dapat lebih fokus dalam mengetahui pengaruhnya sebagai media komunikasi pemasaran terpadu PT. Bank Negara Indonesia (Persero) - Tbk cabang Majene dalam mempengaruhi keputusan konsumen, sehingga dapat mencapai tujuan secara khusus menjadi bank of Choice bagi seluruh kebutuhan finansial konsumen, terutama di Majene Sulawesi Barat. Pada penelitan ini, menggunakan data primer berupa kuesioner dalam pengumpulan datanya, dan desain pengukuran penelitian ini menggunakan skala likert. Seiring tidak diketahuinya jumlah pasti terkait populasi penelitian ini, maka dalam penentuan sampel menggunakan tehnik quota sampling, dalam proses analisis data penelitian yang akan dilaksanakan menggunakan metode analisis eksplanatif, dimana analisis ini bertujuan untuk mengetahui hubungan antar variabel, dengan menggunakan SPSS 23. Dalam penelitian ini ditemukan efek yang signifikan secara statistik dalam elemen intrumen promosi penjualan dan periklanan terhadap keputusan konsumen dalam memilih produk tabungan yang dimiliki PT. Bank Negara Indonesia (Persero) - Tbk.
\end{abstract}

\section{Kata Kunci: Bauran Promosi, Keputusan Konsumen}

\begin{abstract}
This research would like to see the influence of sales promotion and advertising without sideways other variables of the promotional mix, so that it can focus more on knowing its influence as an integrated marketing communication medium pt. Bank Negara Indonesia (Persero) - Tbk Majene branch in influencing consumer decisions, so as to achieve the goal of specifically becoming a bank of Choice for all financial needs of consumers, especially in Majene West Sulawesi. In this study, using primary data in the form of questionnaires in the collection of data, and the design of measurements of this study using likert scale. As the exact number of populations related to this study is unknown, in the determination of samples using quota sampling techniques, in the process of analyzing the research data that will be carried out using the explanative analysis method, where this analysis aims to know the relationship between variables, using SPSS 23. In this study, there was a statistically significant effect in the intrusion element of sales promotion and advertising on consumer decisions in choosing savings products owned by PT. Bank Negara Indonesia (Persero) - Tbk.
\end{abstract}

Keywords: Promotional Mix, Consumer Decisions 


\section{PENDAHULUAN}

Industri jasa merupakan seluruh kegiatan ekonomi yang keluarannya bukan berupa produk fisik atau konstruksi, umumnya dikonsumsi pada saat diproduksi, dan memberikan nilai tambah dalam bentuk seperti kenyamanan, hiburan, ketepatan waktu, atau Kesehatan. (Wilson dkk., 2016). Sama halnya dengan industi jasa perbankan saat ini, banyak memilik penawaran-penawaran yang menarik konsumen dalam menentukan keputusan pembelian, dimana keputusan konsumen sendiri merupakan jalur dimana konsumen bergerak melalui tahap pengambilan keputusan tergantung pada beberapa faktor, termasuk tingkat keterlibatan dan tingkat variasi pencarian (Kotler \& Keller, 2016). Banyaknya berbagai penawaran yang ada pada industri perbankan juga didukung berbagai macam cara dalam memasarkan, termaksud dalam penerapan teori bauran promosi, dalam memasarkan penawaran yang dimiliki, dimana bauran promosi juga sering di sebut sebagai metode komunikasi pemasaran terpadu. Yang didalamnya terdapat metode periklanan, publisitas, pemasaran langsung, promosi penjualan, dan penjualan pribadi (Baker, 2003).

PT. Bank Negara Indonesia (Persero) -Tbk merupakan salah satu perusahaan yang terlibat dalam industi perbankan di Indonesia, perusahaan ini juga merupakan perusahaan yang berorientasi pada konsumen, sehingga berbagai penawaran yang diproduksi berpihak pada konsumen, dan secara tidak langsung dapat menjadi pilihan utama bagi konsumen di dunia industri perbankan, dalam memperkuat market positioning khususnya pada sektor Business Banking. Melalui orientasi pada konsumen dan dibantu dengan tenaga-tenaga handal dan profesional di bidang pemasaran, PT. Bank Negara Indonesia (Persero) - Tbk cabang Majene Sulawesi Barat diharapkan mampu menjadi bank of Choice bagi seluruh kebutuhan finansial di seluruh sektor dengan kualitas pelayanan yang terbaik bagi para konsumen.

Akan tetapi, terdapat fenomena, di mana dalam penyebaran informasi terkait penawaran yang dimiliki oleh PT. Bank Negara Indonesia (Persero) - Tbk cabang Majene, melakukan komunikasi dengan konsumen maupun calon konsumen masih dominan mengandalkan costumer service yang masuk dalam penjualan pribadi, sehingga tidak optimalnya bagian dari bauran promosi lainnya seperti promosi penjualan dan periklanan. Sehingga penyebaran informasi tidak merata.

Guna mendukung PT. Bank Negara Indonesia (Persero) - Tbk cabang Majene menjadi bank of Choice bagi seluruh kebutuhan finansial di seluruh sektor dengan kualitas pelayanan yang terbaik bagi para konsumen, perlunya melakukan pengoptimalisasian proses promosi penjualan dan periklanan yang ada pada PT. Bank Negara Indonesia (Persero) - Tbk cabang Majene, hal tersebut berdasarkan hasil penelitian (Lontoh, 2016) dengan judul analisis pengaruh bauran promosi terhadap keputusan 
pembelian mobil Toyota pada PT. Hasrat abadi manado cabang tandean, mengungkapkan hasil penelitian penjualan pribadi,periklanan, promosi penjualan, hubungan masyarakat dan pemasaran langsung berpengaruh dan signifikan terhadap keputusan pembelian, hal ini tidak selaras dengan hasil penelitan dari, (Kaluku dkk., 2018) dengan judul analisis bauran promosi terhadap keputusan nasabah menggunakan produk unggulan pada bank Syariah mandiri cabang Manado, dengan hasil penelitian menemukan variabel periklanan, promosi penjualan dan hubungan masyarakat tidak berpengaruh terhadap keputusan konsumen.

Fokus dalam penelitian ini adalah, ingin melihat pengaruh promosi penjualan dan priklanan dan menyampingkan variabel lain dari bauran promosi, sehingga dapat lebih fokus dalam mengetahui pengaruhnya sebagai media komunikasi pemasaran terpadu PT. Bank Negara Indonesia (Persero) Tbk cabang Majene dalam mempengaruhi keputusan konsumen, sehingga dapat mencapai tujuan secara khusus menjadi bank of Choice bagi seluruh kebutuhan finansial konsumen, terutama di Majene Sulawesi Barat.

\section{METODE PENELITIAN}

Dalam penelitian ini terdapat permasalahan yang mencakup dominannya komunikasi pemasaran menggunakan personal selling sehingga komunikasi pemasaran lain yang merupakan bagian dari pada bauran pemasaran perlu penelitian lebih lanjut sampai dimana peran komunikasi tersebut. Sumber data penelitian merupakan subyek dari mana dapat diperoleh, pada penelitan ini menggunakan data primer berupa kuesioner dalam pengumpulan datanya, dan desain pengukuran penelitian ini menggunakan skala likert. Seiring tidak diketahuinya jumlah pasti terkait populasi penelitian ini, maka dalam penentuan sampel menggunakan tehnik quota sampling, dimana peneliti menentukan jumlah sampel penelitian sebesar 100 responden dan telah dilakukan uji analisis faktor dan memperoleh hasil > 0,60 dan diyatakan layak untuk dilanjutkan menurut (Hair, 2014). Dalam proses analisis data penelitian yang akan dilaksanakan menggunakan metode analisis eksplanatif, dimana analisis ini bertujuan untuk mengetahui hubungan antara dua variabel atau lebih (Putu Agung, 2012), dengan menggunakan SPSS 23.

\section{HASIL DAN PEMBAHASAN}

Pemasaran adalah sistem kegiatan yang saling terkait, dirancang untuk mengembangkan, mempromosikan danmendistribusikan barang da jasa kepada sekelompok konsumen (Mathur, 2008), dalam hal ini terkait promosi, bauran promosi memiliki capaian dalam menginformasikan produk dan jasa. Menurut (Martha dkk., 2019) Bauran promosi terdiri dari periklanan, penjualan langsung, 
promosi penjualan, dan publisitas. Jasa adalah serangkaian kegiatan yang berupa perbuatan, upaya ataupun pertunjukan, (Hoffman \& Bateson, 2011).

Berdasarkan tinjauan literatur, bauran promsoi terdiri dari periklanan, penjualan langsung, promosi penjualan, dan publisitas. Dalam penelitaan ini, penulis mengambil dua variabel yang akan di uji, yaitu promosi penjualan dan periklanan.

\section{Validitas dan Reabilitas}

Pada penelitian kuantitaif, kriteria yang utama dari hasil penelitian adalah valid, dan reliabel, (Sugiyono, 2012).

Tabel 1. Validitas dan Reabilitas

\begin{tabular}{lcccc}
\hline \multirow{2}{*}{ Variabel } & \multicolumn{2}{c}{ Validitas } & Cronbach's Alpha & \multirow{2}{*}{ Ket } \\
\cline { 2 - 4 } & & $\mathrm{r}_{\text {hitung }}>\mathrm{r}_{\text {tabel }}(0.163)$ & $>0.60$ & \\
\hline \multirow{3}{*}{ Promosi } & $\mathrm{X} 1$ & & 0.810 & Reliable \\
\cline { 2 - 5 } Penjualan & $\mathrm{X} 1.1$ & 0.797 & & Valid \\
& $\mathrm{X} 1.2$ & 0.868 & & Valid \\
& $\mathrm{X} 1.3$ & 0.870 & & Valid \\
\hline \multirow{4}{*}{ Periklanan } & $\mathrm{X} 2$ & & & Reliable \\
\cline { 2 - 5 } & $\mathrm{X} 2.1$ & 0.782 & & Valid \\
& $\mathrm{X} 2.2$ & 0.822 & & Valid \\
& $\mathrm{X} 2.3$ & 0.802 & & Valid \\
\hline \multirow{3}{*}{ Keputusan } & Y1 & & & Reliable \\
\cline { 2 - 5 } Konsumen & Y1.1 & 0.852 & & Valid \\
& Y1.3 & 0.877 & & Valid \\
& & 0.873 & & Valid \\
\hline
\end{tabular}

Menurut (Ghozali, 2013), dalam pengukuran validitas penelitian pada Tabel 1, dilakukan dengan cara mengkorelasikan antar skor butir pertanyaan dengan skor total variabel. Uji signifikansi dilakukan dengan membandingkan nilai $\mathrm{r}$ hitung dengan $\mathrm{r}$ tabel untuk degree of freedom $(\mathrm{df})=\mathrm{n}-2, \mathrm{n}$ adalah jumlah sampel. Jadi df yang di peroleh adalah $100-2=98$ dengan alfa sebesar 5\% maka menghasilkan nilai $\mathrm{r}$ tabel (uji dua sisi) sebesar 0.1966 dengan ketentuan $\mathrm{t}$ hitung $>$ dari $\mathrm{r}$ tabel (0.966) = valid.

Reabilitas jika merujuk ke definisi awal, menyatakan bahwa instrument penelitian yang digunakan dapat mengukur sesuatu yang dapat diukur secara konsisten dari waktu kewaktu, (Saifuddin, 2012). Syarat kualifikasi suatu instrument penelitian sebagai pengukur adalah tetap konsisten. Pengujian reabilitas instrument penelitian ini dengan menggunakan rumus Cronbach alpha karena instrumen penelitian ini berbentuk kuesioner/angket dan menggunakan skala bertingkat. Hasil dari uji reabilitas memperoleh nilai Cronbach alpha $>0.60$ dan dinyatakan setiap intrumen penelitian ini reliable untuk dilanjutkan ketahap analisis selanjutnya. 


\section{Uji Hipotesis}

\section{Pengujian Hipotesis Secara Simultan (Uji F)}

Pengujian ini dilakukan untuk mengetahui pengaruh seluruh variabel independent yang terdapat dalam model penelitian secara Bersama-sama (simultan) berpengaruh ataupun tidak terhadap variabel dependen. Dala menentuka hsil penelitian dalam uji ini, dengan menggunakan tingkat signifikan sebesar 5\% (0.05). F tabel di peroleh dengan ketentuan df1= 2 (variabel independent) dengan df $2=\mathrm{n}-\mathrm{k}-1$. Apabila dalam hasil penelitian di temukan $\mathrm{F}$ hitung $<\mathrm{F}$ tabel atau tingkat signifikan $\mathrm{F}>0.05$, maka $\mathrm{H}_{0}$ diterima. Apabila $\mathrm{F}$ hitung $>\mathrm{F}$ tabel dan tingkat signifikan $<0.05$, maka $\mathrm{H}_{0}$ ditolak.

Hasil penelitian yang telah dilakukan menunjukkan bahwa keputusan konsumen dapat tumbuh dari penerapan variabel promosi penjualan dan periklanan. Jika dilakukan secara intensif tanpa mendominankan suatu program komunikasi pemasaran lainnya.

\section{Tabel 2. Hasil Uji Hipotesis Secara Simultan (Uji F)}

\begin{tabular}{lccccc}
\hline \multicolumn{1}{c}{ Model } & Sum of Squares & df & Mean Square & F & Sig. \\
\hline Regression & 287.777 & 2 & 143.888 & 77.880 & 0.000 \\
Residual & 179.213 & 97 & 1.848 & & \\
\hline Total & 466.990 & 99 & & & \\
\hline
\end{tabular}

Berdasarakan hasil diatas tertera pada Tabel 2, menunjukkan bahwa angka $\mathrm{F}$ hitung yang diperoleh 77.880 dan $\mathrm{F}$ tabel sebesar 3.09, maka dapat dipastikan $\mathrm{F}$ hitung (77.880) > dari $\mathrm{F}$ tabel (3.09) dengan tingkat signifikansi sebesar $0.000<0.05$ ini berarti bahwa $\mathrm{H}_{0}$ ditolak dan $\mathrm{H}_{\mathrm{a}}$ diterima. Dengan demikian dapat menerangkan variabel promosi penjualan dan periklnan berpengaruh terhadap keputusan konsumen pada PT. Bank Negara Indonesia (Persero) - Tbk cabang Majene.dapat diterima.

Pengujian Hipotesis Secara Parsial (Uji t)

Pengujian ini dilakukan untuk mengetahui tingkat peran signifikan secara parsial antara variabel independent terhadap variabel dependent. Darar pengambilan keputusan untuk menguji hipotesis secara parsial menggunakan tingkat signifikan sebesar 5\% (0.05) dengan menggunakan dua sisi. $\mathrm{t}$ tabel menggunakan degree of freedom $(\mathrm{df})=\mathrm{n}-\mathrm{k}-1$. Apabia $\mathrm{t}$ hitung $>\mathrm{t}$ tabel atau tingkat signifikansi $<0.05$, maka $\mathrm{H}_{0}$ ditolak dan $\mathrm{H}_{\mathrm{a}}$ diterima. 
Tabel 3. Hasil Uji Hipotesis Secara Parsial (Uji t)

\begin{tabular}{cccccc}
\hline \multicolumn{1}{c}{ Variabel } & $\mathrm{B}$ & Std. Error & t Hasil & Sig. & Ket \\
\cline { 1 - 4 }$($ Constant $)$ & 1.588 & & & & \\
\hline $\mathrm{X} 1$ & 0.425 & 0.071 & 5.988 & 0.000 & Sig. \\
$\mathrm{X} 2$ & 0.431 & 0.078 & 5.552 & 0.000 & Sig. \\
\hline $\mathrm{R}=0.785$ & & Sig. $\mathrm{F}=0.000$ & & Sampel $=100$ \\
$\mathrm{R}$ Square $=0.616$ & & F hitung $=77.880$ & & $\mathrm{t}$ tabel $=1.660$ \\
Adjusted R Square $=0.608$ & F tabel $=3.09$ & & $\alpha=0.05$
\end{tabular}

Nilai t hitung X1 (promosi penjualan) menunjukkan angka 5.988, dan t tabel sebesar 1.660. Dengan demikian $\mathrm{t}$ hitung (5.988) $>\mathrm{t}$ tabel (1.660) dan nilai signifikansi $0.000<0.05$. hal tersebut menyatakan promosi penjualan berpengaruh terhedap keputusan konsumen pada PT. Bank Negara Indonesia (Persero) - Tbk cabang Majene.

Hasil pengujian hipotesis secara parsial dengan uji t menunjukkan nilai hitung yang memiliki pengaruh terhadap keputusan konsumen. Hasil ini sesuai dengan hasil penelitian (Nour, 2014) yang menyatakan signifikan secara statistik terhadap keputusan konsumen.

Nilai t hitung X2 (periklanan) menunjukkan angka 5.552, dan t tabel (1.660) dan nilai signifikansi $0.000<0.05$. hal tersebut menyatakan periklanan berpengaruh terhadap keputusan konsumen pada PT. Bank Negara Indonesia (Persero) - Tbk cabang Majene.

Hasil pengujian hipotesis secara parsial menunjukkan nilai hitung yang memiliki pengaruh terhadap keputusan konsumen, selaras dengan hasil penelitian (Erwin dkk., 2019) yang menunjukkan variabel periklanan secara signifikan berpengaruh teradap keputusan konsumen dalam memilih jasa.

\section{KESIMPULAN DAN SARAN}

Dalam penelitian ini terdapat pengaruh/efek yang signifikan secara statistik dalam elemen intrumen promosi penjualan dan periklanan yang dilakukan PT. Bank Negara Indonesia (Persero) - Tbk cabang Majene. Terhadap keputusan konsumen dalam memilih produk tabungan yang disediakan oleh PT. Bank Negara Indonesia (Persero) - Tbk.

Hal ini penting untuk PT. Bank Negara Indonesia (Persero) - Tbk cabang Majene untuk memperhatikan dalam melakukan praktik komunikasi pemasaran terpadu atau bauran promosi terutama pada elemen promosi penjualan dan periklanan untuk meningkatkan pengguna tabungan, serta dapat menjadi bank of Choice bagi seluruh kebutuhan finansial konsumen, terutama di Majene Sulawesi Barat. Tanpa harus mendominankan beberapa elemen lain dari bauran promosi, seperti costumer service sebagai komunikasi terdepan selama ini. 


\section{DAFTAR PUSTAKA}

Baker, M. J. (Ed.). 2003. The marketing book (5th ed). Butterworth-Heinemann.

Erwin, Permata, S. U., Tahawa, T. H. B., \& Khaldun, R. I. 2019. Analisis Pengaruh Promosi Penjualan Dan Periklanan Terhadap Keputusan Konsumen Dalam Memilih Jasa Service Pada Pt. Astra Internasional. 1, 8.

Ghozali, I. 2013. Aplikasi Analisis Multivariate dengan Program SPSS (7 ed.). Badan Penerbit Universitas Diponegoro.

Hair, J. F. (Ed.). 2014. Multivariate data analysis (7. ed., Pe). Pearson.

Hoffman, K. D., \& Bateson, J. E. G. 2011. Services marketing: Concepts, strategies, \& cases (4th ed). South-Western.

Kaluku, F., Mandey, S. L., \& Soepeno, S. 2018. Analisis Bauran Promosi Terhadap Keputusan Nasabah Menggunakan Produk Unggulan Pada Bank Syariah Mandiri Cabang Manado. 10.

Kotler, P., \& Keller, K. L. 2016. Marketing Management (fifteenth). Pearson Education Limited.

Lontoh, M. N. 2016. Analisis Pengaruh Bauran Promosi Terhadap Keputusan Pembelian Mobil Toyota Pada Pt. Hasjrat Abadi Manado Cabang Tendean. 16(01), 11.

Martha, R. E., Evanita, S., \& Patricia, D. 2019. The Influence of Promotion Mix towards Purchasing Decision of Indihome product in Telkom Region of Padang City. Proceedings of the 2nd Padang International Conference on Education, Economics, Business and Accounting (PICEEBA-2 2018). Proceedings of the 2nd Padang International Conference on Education, Economics, Business and Accounting (PICEEBA-2 2018), Padang, Indonesia. https://doi.org/10.2991/piceeba2-18.2019.53

Mathur, U. C. 2008. Business to Business Marketing. New Age International.

Nour, M. I. 2014. The Impact of Promotional Mix Elements on Consumers Purchasing Decisions. International Business and Management, 9.

Putu Agung, A. A. 2012. Metodologi Penelitian Bisnis (1 ed.). UB Press.

Saifuddin, A. 2012. Metode Penelitian. Pustaka Pelajar.

Sugiyono. 2012. Metode Penelitian Bisnis (16 ed.). Alfabeta.

Wilson, A. M., Zeithaml, V. A., Bitner, M. J., \& Gremler, D. D. 2016. Services marketing: Integrating customer focus across the firm (Third european edition). McGraw-Hill. 